\title{
Camel Slaughtering Practices and Meat Production in Eastern Ethiopia
}

\author{
Mitiku Eshetu Guya ${ }^{1 *}$ and Getachew Neme ${ }^{2}$ \\ ${ }^{1}$ School of Animal and Range Sciences, Haramaya University, P.O. Box: 167, Dire Dawa, Ethiopia \\ ${ }^{2}$ School of Food Science, Post-Harvest Technology and Process Engineering, Haramaya University, \\ P.O. Box 138, Dire Dawa, Ethiopia
}

\begin{tabular}{|c|c|}
\hline $\begin{array}{ll}\text { Abstract } & \text { Abtris }\end{array}$ & Article Information \\
\hline $\begin{array}{l}\text { This study was conducted in Ethiopian Somali (Jigjig and Shinile Zones) and Afar regions from } \\
\text { April to June } 2012 \text { to assess camel slaughtering practices and camel meat processing and } \\
\text { preservation technologies in the regions. The result of this study revealed that } 89 \% \text { of camels } \\
\text { slaughtered in Jigjiga and Dire Dawa municipal slaughter houses had score of two body } \\
\text { condition score (BCS) which indicates poor body condition of the slaughter camels. In these } \\
\text { slaughter houses, camels were slaughtered first by immobilizing the camel by cutting the hind } \\
\text { leg at the Achilus tendon. Then the animal becomes immobile and guided to slaughtering floor } \\
\text { to cut its throat. Subsequently, flying, evisceration and dressing undertaken. Then the meat } \\
\text { was transported to butcher house. The butcher house could sell the meat either fresh or } \\
\text { traditionally process and preserve it. Preservation of meat was conducted by boiling the meat } \\
\text { to reduce the water content as well as to reduce the water activity of the meat. Butter was also } \\
\text { added while boiling to enhance flavor and eating quality of the product. This preservation } \\
\text { method was common in Ethiopian Somali region among Somali tribes and the preserved } \\
\text { camel meat is called Mukmud or Muremure. This product is claimed to have up to six months } \\
\text { shelf life. While slaughtering camel, the animal was suffering from an excruciating pain from } \\
\text { broken cut hock as well as from the act of cutting the throat. Therefore, camel slaughtering } \\
\text { practice in Somali Region and Dire Dawa Administrative region was not follow ethical animal } \\
\text { slaughtering practice and breach animal welfare protection law. To curb this problem, } \\
\text { immediate interventions need to be taken to stop such cruel act of cutting the legs of live } \\
\text { animal while the animal is conscious and feel the pain. There was no practice of cutting } \\
\text { Achilles tendon in Afar region. } \\
\text { Copyright@2015 STAR Journal, Wollega University. All Rights Reserved. }\end{array}$ & $\begin{array}{l}\text { Received : 03-06-2015 } \\
\text { Revised : 04-09-2015 } \\
\text { Accepted : 23-09-2015 } \\
\text { Keywords: } \\
\text { Animal welfare } \\
\text { Meat preservation } \\
\text { Muremure } \\
\text { *Corresponding Author: } \\
\text { Mitiku Eshetu Guya } \\
\text { E-mail: } \\
\text { eshetumit@yahoo.com }\end{array}$ \\
\hline
\end{tabular}

\section{INTRODUCTION}

Ethiopia possesses 4.5 million heads of camel and majority of these camels are found in the Eastern part of Ethiopia mainly in Ethiopian Somali and Afar Regions. Camels are slaughtered to produce meat especially during holidays and festivals. Camels are mainly reared for production of milk and milk products. Meat production from camel was not common in the pastoral and agropastoral production system of Ethiopia. But the current national economic growth coupled with increased demand for camel meat from neighboring Middle East countries awaken us to reconsider camel for meat production.

Camel slaughtering in local abattoirs was investigated and found to be substandard and special way of immobilizing camel was practiced in Jigjiga, Hartichek and Dire Dawa abattoirs. In this slaughter practice, the camel hind legs were first cut at Achilus tendon to immobilize the animal. Then the camels were guided to slaughtering floor where cutting of the throat takes place. In this slaughter method the animal suffer from pain of the broken hind legs. Therefore, slaughter camels need due attention to control and to prevent such needless pre-slaughter suffering.
Camel has a big role in earning foreign currency through export of live camel and in 2011, of the total exported live animals, camel accounted for $13 \%$ and $25 \%$ to the revenue generated (NBIIA, 2011). Future research efforts need to focus on exploring the potential of the camel as a source of meat through multi-disciplinary research into efficient production systems, and improved meat technology and marketing.

In addition camel meat is becoming popular among consumers due to its medicinal and health enhancing properties. According to Kurtu (2004) camel meat is considered as a high quality food with medicinal value and a least cost source of meat in Jigjiga and Harar towns. Moreover, the price of camel meat is increasing from time to time as a result of increased urbanization, economic growth and consumers' awareness about the unique quality of camel meat compared to the common meat of cattle and small ruminants. But the slaughter practice of camel is not well documented and there is no sufficient information. Somali and Afar region are the main camel producing regions of the country and possess majority of the camel population. This research is, therefore, designed to evaluate camel meat production and to 
Mitiku Eshetu Guya and Getachew Neme

elucidate procedures followed to slaughter camel in the light of animal handling ethics and welfare issues.

\section{MATERIALS AND METHODS}

\section{Description of the Study Area}

Jigjiga is the capital city of the Ethiopian Somali National Regional State and found $630 \mathrm{~km}$ East of Addis Ababa at a latitude of $9^{\circ} 21^{\prime} \mathrm{N}$ and longitude of $42^{\circ} 48^{\prime} \mathrm{E}$. The area is characterized by unreliable and erratic rainfall with precipitation ranging from 300 to $600 \mathrm{~mm}$ per annum (Bekele, 2001). Altitude of Jigjiga Wereda ranges from 500-1500 meter above sea level (masl) and majority of the camel herders are Somali ethnic groups. Numerically camels are the most abundant domestic animals in the area followed by goat. In Jigjiga city there is one municipal slaughter house where all livestock species are slaughtered and then distributed to the different butcher houses. Slaughtering of animals was takes place starting from $2 \mathrm{AM}$ and completed early in the morning.

Dire Dawa is one of commercial city in the Eastern part of Ethiopia. It is found in $515 \mathrm{~km}$ East of Addis Ababa at $9^{\circ} 27^{\prime} \mathrm{N}$ latitude and $42^{\circ} 89^{\prime} \mathrm{E}$ longitude. It is bounded in the north west and east by Somali National Regional State and in the north by Oromiya National Regional State. The mean annual temperature and precipitation were about 25.3 and $640 \mathrm{~mm}$, respectively (IRDMP, 2004). Dire Dawa town has one municipal slaughter house where different livestock species are slaughtered and distributed to different butcher houses. Pastoralists and agro-pastoralis in Dire Dawa Administrative town and in Shinile Zone were the main supplier of camel for Dire Dawa municipal slaughterhouse.

\section{Method of Data Collection}

The overall objective of this paper is to review camel meat production and to assess camel slaughtering practices to recommend possible interventions. To this effect meat production data were collected from Dire Dawa Administrative, Ethiopian Somali and Afar Regional States. Meat vendors, key informants were interviewed and focused group discussions were undertaken to collect data on method of camel slaughtering, meat processing and preservation methods. Moreover data on use of preserved meat, type of meat used for the preparation preserved meat products were collected. Data on slaughter practices were collected from Jigjiga and Dire Dawa municipal slaughterhouses through observation and interview using pre-tested questionnaire. Moreover, secondary data were collected and reviewed.

\section{Body Condition Score of Slaughter Camels}

Body condition score (BCS) of camels was assessed following six scale scoring method developed by Faye et al (2001) where zero is for very thin camel and five for fat camel.

\section{Data Analysis}

Data collected from slaughterhouses and meat preservation methods were analyzed using descriptive statistics.

\section{RESULT AND DISCUSSION}

\section{Camel Meat Production}

The average number of camels slaughtered in Jigjiga and Dire Dawa municipal slaughter houses was two and three camels per day, respectively. Camel takes longer
Sci. Technol. Arts Res. J., July-Sep 2015, 4(3): 123-128

time to reach slaughter weight and age, hence meat production from camel is costly and less common or less heads of camel slaughtered per day. In rural area slaughtering of camel is also restricted to special occasions like holidays and wedding. Many authors indicated that camel meat, especially young camel meat, is similar in taste and texture to that of beef. The average birth weight is $35 \mathrm{~kg}$, and adult male and female camels weigh $486 \pm 81.3 \mathrm{~kg}$ and $427 \pm 62.2 \mathrm{~kg}$, in Jigjiga area and $384 \pm 80.8 \mathrm{~kg}$ and $326 \pm 62.9 \mathrm{~kg}$ in Shinile area, respectively (Tezera Getahun, 1998). The average dressing percentage found to be $50-55 \%$.

Many authors indicated that camel meat, especially young camel meat, is similar in taste and texture to that of beef. The amino acid and mineral contents of camel meat are often higher than beef, probably due to lower intramuscular fat levels as most of the fat is deposited in the hump leaving minimal marbling of the red meat. Due to the low fat content, camel meat is therefore believed to be nutritionally healthier and is getting more acceptance than before.

In Somali region there is a long tradition of processing camel meat into stable dried and oiled meat products This processed meat product is highly regarded and present to honorable guests and wife presents to her husband as a symbol of respect.

\section{Body Condition of Slaughtered Camels}

The result of this study indicated that out of the total 25 and 30 camels slaughtered in Jigjiga and Dire Dawa slaughterhouses during the study period, $92 \%$ and $86.66 \%$ were having two BCS (thin camels), respectively (Table 1). The remaining slaughtered camels BCS were three (good body condition camel). Therefore, it is possible to conclude that majority of slaughtered camels were of poor body condition and unfit for production of good quality and quantity meat. Such meat will have poor palatability and short shelf life.

Table 1: Body condition of camels slaughtered at Jigjiga and Dire Dawa slaughter houses

\begin{tabular}{|c|c|c|c|c|c|c|}
\hline \multirow{3}{*}{$\begin{array}{l}\text { Body } \\
\text { condition } \\
\text { score }\end{array}$} & \multicolumn{4}{|c|}{ Abattoir } & \multirow{2}{*}{\multicolumn{2}{|c|}{$\begin{array}{c}\text { Total } \\
\text { averaqe }\end{array}$}} \\
\hline & \multicolumn{2}{|c|}{ Jigjiga } & \multicolumn{2}{|c|}{ Dire Dawa } & & \\
\hline & $\mathrm{N}=25$ & $\%$ & $\mathbf{N}=30$ & $\%$ & $\mathrm{~N}=55$ & $\%$ \\
\hline 0 & 0 & 0 & 0 & 0 & 0 & 0 \\
\hline 1 & 0 & 0 & 0 & 0 & 0 & 0 \\
\hline 2 & 23 & 92 & 26 & 86.66 & 49 & 89.09 \\
\hline 3 & 2 & 8 & 3 & 10.00 & 5 & 9.09 \\
\hline 4 & 0 & 0 & 1 & 3.33 & 1 & 1.81 \\
\hline 5 & 0 & 0 & 0 & 0 & 0 & \\
\hline
\end{tabular}

Type of camel slaughtered in Jigjiga and Dire slaughter house were found to be of poor body condition and aged camels. The number of camels slaughtered per day was significantly lower than other livestock species especially cattle, goat and sheep. The respondents indicated the reason for slaughtering of camels in poor body condition was that young and good body condition camels were used for legal as well as for illegal crossborder export trade as the export market fetch more money to the producer. Hence there was fierce competition between the local and cross-border export market. 


\section{Camel Meat Consumption}

In the study area, unless there is special occasion camel was not slaughtered. Hence camel was slaughtered during holidays, wedding, mourning (death of prominent and celebrity personality) and in urban municipalities' slaughter houses (Table 2).

In Afar region, camels are slaughtered by a group of young men who intended to build up their body for defending the community from possible enemy attack. In this practice a total of 10 youth make a group and depart to a forest area having a slaughter camel. In the forest they slaughter camel and consume the camel meat without mixing it with other food ingredients. While eating camel meat in the forest drinking of water is strictly prohibited due to the perception that drinking water in such occasion can have negative impact on their performance. This practice is called Dasiga. There was no such practice in Somali region, but preservation of camel meat in the form of dried meat is very common and widely practiced in Jigjiga and to some extent in Dire Dawa and Shinile. This processed camel meat is highly regarded and can be kept for a long period of time with extended shelf life where there is no refrigeration facilities coupled with high ambient temperature suitable for spoilage microorganisms. Slaughtering of camel in early pregnancy was practiced in Afar region with the assumption that pregnant camel produces good quality meat.

Camel was slaughtered for different reasons (Table 2). In some special circumstances camel was slaughtered during circumcision of children, and to feed injured and bone fractured person mainly due to conflict. A camel may be slaughtered if it gets broken due to accident or fighting.

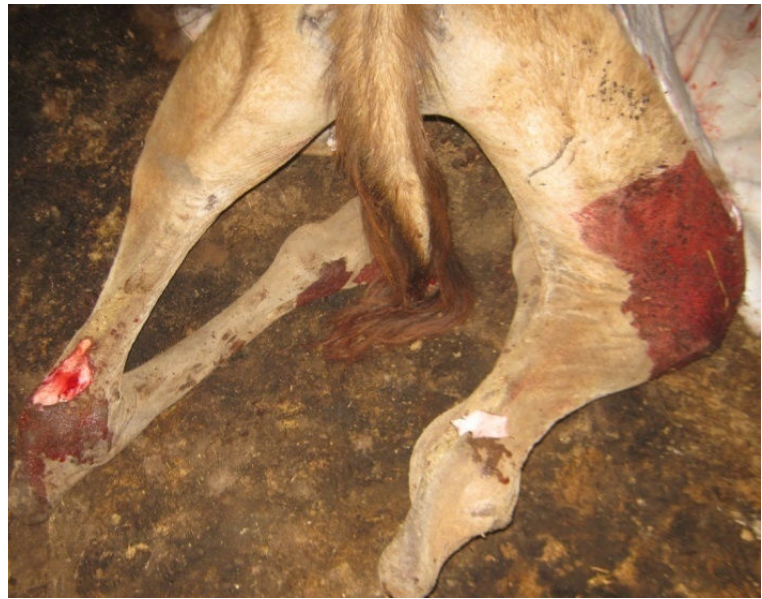

Figure 1: Slaughter camel restrained after the Achilles tendon was cut

Result of observation of Dire Dawa and Jigjiga Municipal slaughterhouse revealed that these slaughter houses were not fulfilling the requirement for standard slaughterhouse. Hence it can negatively influence humane handling of slaughter animals. This leads to mishandling of slaughter animals which will have impact on the quality and quantity of meat harvested. This could raise issue of slaughter animal welfare, how slaughter animals are treated in slaughterhouses found in the country as whole.

There was no exception to slaughter camel even it was the worst if we consider what has been practiced in
Table 2: Purpose of slaughtering of camel in the study areas

\begin{tabular}{|c|c|c|c|c|c|c|}
\hline \multirow{2}{*}{$\begin{array}{l}\text { Purpose of camel } \\
\text { slaughtering }\end{array}$} & \multicolumn{2}{|c|}{$\begin{array}{l}\text { Jigjiga } \\
(\mathrm{N}=30)\end{array}$} & \multicolumn{2}{|c|}{$\begin{array}{l}\text { Shinile } \\
(\mathrm{N}=30)\end{array}$} & \multicolumn{2}{|c|}{$\begin{array}{c}\text { Afar } \\
(\mathrm{N}=30)\end{array}$} \\
\hline & $\mathbf{N}$ & $\%$ & $\mathbf{N}$ & $\%$ & $\mathbf{N}$ & $\%$ \\
\hline Holiday & 30 & 100 & 30 & 100 & 30 & 100 \\
\hline Wedding & 25 & 83.33 & 15 & 50 & 21 & 70 \\
\hline $\begin{array}{l}\text { Mourning for death } \\
\text { renowned person }\end{array}$ & 30 & 100 & 25 & 83.33 & 0 & 0 \\
\hline $\begin{array}{l}\text { Youth body } \\
\text { building }\end{array}$ & 0 & 0 & 0 & 0 & 30 & 100 \\
\hline
\end{tabular}

$\mathrm{N}=$ Number of respondents

\section{Camel Slaughtering practice}

Camel slaughter procedure followed at Jigjiga and Dire Dawa slaughterhouse was that first the animal leg was cut at Achilles tendon (hock) to immobilize (figure 1) and then the animal became unable to walk and drag its hind legs (figure 2). Restraining of slaughter camel was done by holding the neck and putting the animal in squat position after which severing of the neck was undertaken. In this practice, it was observed that the animal was conscious and suffering from the excruciating pain. Such method was practiced in Jigjiga, Hartichk and Dire Dawa slaughterhouses. There was no practice of cutting Achilles tendon in Afar region. With regard to meat quality, it is possible to harvest wholesome and nutritious meat whenever slaughter animals are treated as per humane slaughter procedure as pre-mortem handling of animals has determinant effect on meat quality and subsequent meat processing.

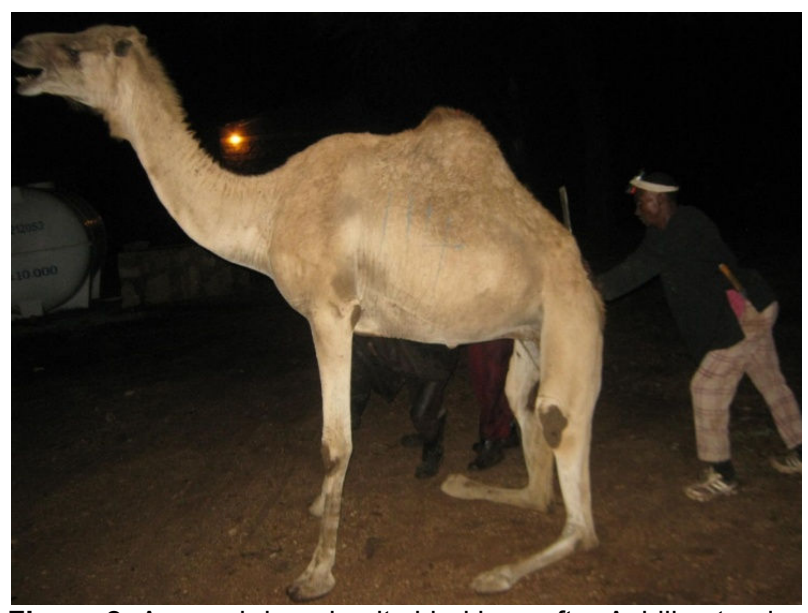

Figure 2: A camel dragging its hind legs after Achilles tendon cut at hock

Jigjiga and Dire Dawa Municipal slaughter houses. In this slaughterhouses camel slaughtering begin with cutting the Achilles tendon at hock to immobilize the animal. Then severing of the neck takes place with little effort to immobilize the camel. The British Humane Slaughter Act of 1933, make stunning compulsory, and permit use of modern methods, such as the captive bolt pistol and electric tongs. The wording of the 1933 act specifically outlaws the poleaxe. Hence Ethiopia need also to develop such regulation to protect slaughter camels from such malpractices prevailing in Jigjiga and Dire Dawa slaughterhouses in particular and the whole animal slaughtering practices in the country in general. 


\section{Mitiku Eshetu Guya and Getachew Neme}

In USA Humane Method of Livestock Slaughter Act (HMLSA), the first Human Slaughter Act (1902) stated that either all animals are rendered insensible to pain or by slaughtering in accordance with the ritual requirements of the Islamic and Jewish faith whereby the animal suffers loss of consciousness by anemia of the brain caused by the simultaneous and instantaneous severance of the carotid arteries with a sharp instrument and handling in connection with such slaughtering.

According to the law, animals should be stunned into unconsciousness prior to their slaughter to ensure a death with less suffering than in killing methods used earlier. The most common methods are electrocution and $\mathrm{CO}_{2}$ stunning for swine and captive bolt stunning for cattle, sheep, and goats. An animal is considered properly stunned when there is no "righting reflex"; that is, the animal must not try to stand up and right itself. Only then can it be considered fully unconscious. It can then proceed down the line, where slaughterhouse workers commence in cutting up its body.

Ethical concern for animals is often based on assessment of their mental capacities, especially the capacity to feel pain consciously (Allen, 1998). Even though the methods used for slaughtering livestock species such as cattle, sheep and pigs have improved considerably (Gregory, 1998), there is no government policy that protect animal rights including slaughtering of meat animals in Ethiopia. Hence animal slaughtering practices differ from region to region.

Animals should move quietly at a walk through pens and races with a minimum of visible excitement or agitation. Most animals should walk calmly into a stunning pen or a restrainer without the use of an electric goad (Gregory, 1998).

The importance of reducing stress during slaughter is clear. In pigs, reducing excitement and agitation during handling in the stunning race will improve welfare and help to preserve meat quality (Barton-Gade, 1984; Grandin, 1994). A study by Warriss et al (1994) indicated that the sound level of vocalizing pigs in a slaughter plant was correlated with reduced pork quality. Furthermore, Voisinet et al (1997) found that cattle which become agitated during handling and restraint had tougher meat, and more borderline dark cutters. In many different pork slaughter plants, it was observed that reducing the use of electric goads and preventing pig pile-ups in the stunning race resulted in a reduction of pale soft exudative meat (PSE) by approximately $10 \%$. Pork slaughter-plant managers have reported that when handling practices were improved, $10 \%$ more pork was accepted for export to Japan. Even though such information is lack in camel meat quality in relation to mishandling of slaughter camel.

Camels were slaughtered on concert floor (Dire Dawa slaughterhouse) and even on dusty floor (Jigjiga slaughterhouse). Flying, dressing and cut up were done on concrete floor. Such practices adversely affect meat quality. Both slaughterhouses workers indicated that new slaughter houses were under construction.

\section{Afar}

First the camel is guided to crouch/squat and then tightly tie the legs to immobilize. Then severing of the neck at atlas region and then cut at the bottom. The
Sci. Technol. Arts Res. J., July-Sep 2015, 4(3): 123-128

respondents also reported that cutting of Achilles tendon was not practiced in Afar region. But cutting of Achilles tendon was practiced for aggressive slaughter cattle.

\section{Meat Fabrication}

The result of the study conducted to assess camel meat fabrication showed that there are 12 main cut up at Jigjiga and Dire Dawa Slaughter houses. These are four legs; two ribs; two loins; two sirloins; and two sternums. Digestive organs were mostly regarded as inedible and wasted away except some organs like liver which was consumed in raw state in Afar region.

Meat fabrication at Dire Dawa slaughter house was in the following order:

1. Cut Achilles tendon

2. Severing the neck

3. Totally separate the neck along with the head from the body

4. Cut the leg at hock \& knee

5. Flying

6. Removal of forelegs with scapula

7. Removing ribs coverings (M. Latissimus dorsi and M. External abdominal oblique)

8. Cutting the ribs into two parts

9. Removal of spinal cords

10. Removal of internal organs

11. Separation of hind legs

\section{Camel Meat Processing}

Result of focus group discussion conducted in Jigjiga, Hartichek and Dire Dawa revealed that preparation of dried processed preserved camel meat was common in these areas (Figure 3 and 4). For example in Hartichek there were people involved in muremure (figure 5) production and marketing. In Dire Dawa this dried preserved meat can be purchased from open market. It was claimed to have medicinal values to sick people especially for recovering from bone fracture, and from weakness and depressed immunity. Moreover, during wedding wife present this processed meat to her husband to express her regard and respect. This type of processed meat was also being exported to Somali and even to Europe as per reported by some of respondents in the study area. Some respondents also indicated that muremure can prevent hypertension. But in Afar region there was no tradition of processing camel meat.

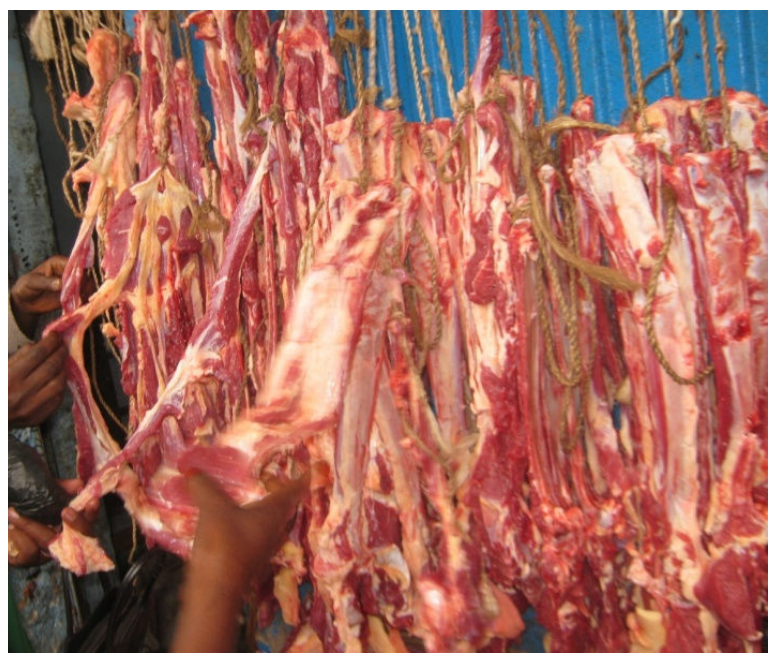

Figure 3: Hanging of camel meat using robes at Jigjiga meat Market 
Mitiku Eshetu Guya and Getachew Neme

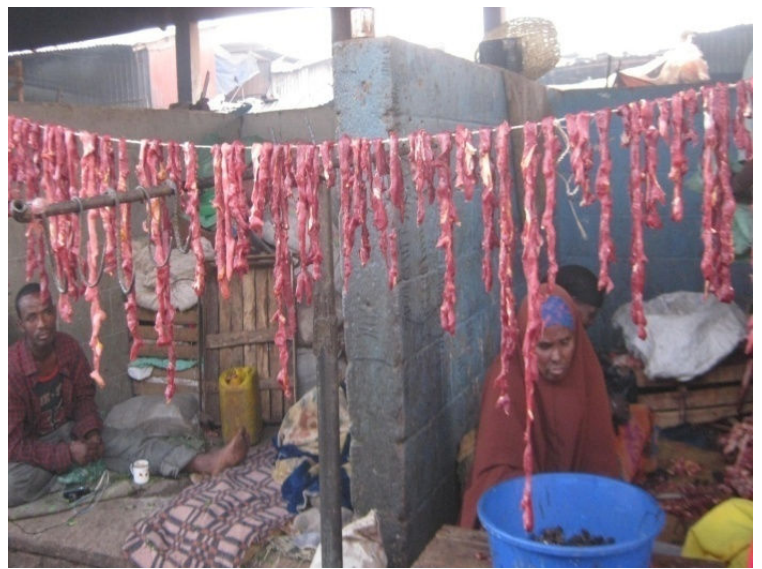

Figure 4: Methods of cutting meat for making Muremure

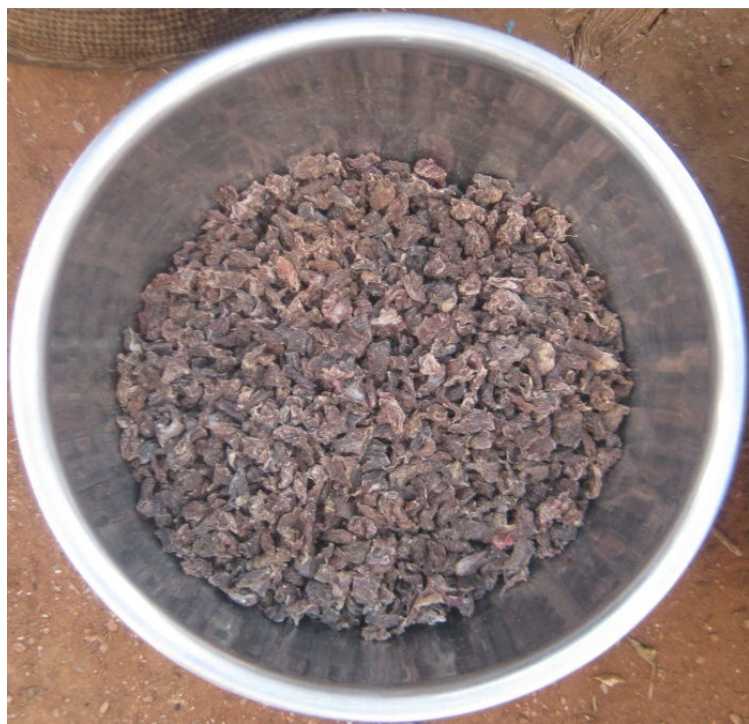

Figure 5: Muremure meat after processing

\section{Camel Hide}

Flaying of camel hide was conducted by cutting it into small pieces without giving due care to its quality in Jigjiga, Dire Dawa, and Afar region (figure 6). The result of group discussion indicated that camel hide was not processed into leather as done for cattle hide and small ruminant skin, but only locally processed to manufacture some local containers, shoe and belts. In some region of afar, camel hide was not properly flayed and used for nothing but abandoned to hyena. This attribute for poor attention to camel hide to harvest quality and quantity hides that could be further processed to manufacture good quality leather products. Some literature indicated that camel hide is as strong as cattle hide and even stronger and thicker. There is also lack of information on the properties of camel hide which renders it to be less important in the face of lucrative market and increasing demand for leather products in the country.

According to Gitao (2006) camel hides are an important resource that could contribute a significant income to pastoralists if there is a reliable market and if they are properly cured. Foxwell (1999) observed that pastoralist use poor methods of curing camel hides leading to poor quality of hides as a result of this many tanneries have rejected camel hides. Camel hides have
Sci. Technol. Arts Res. J., July-Sep 2015, 4(3): 123-128

more fats than cow hides or goats skins and unless it is well removed, the hides rot (Foxwell, 1999). For camel keepers to get maximum profit from camel hides proper curing methods, flaying and proper animal husbandry practices are paramount.

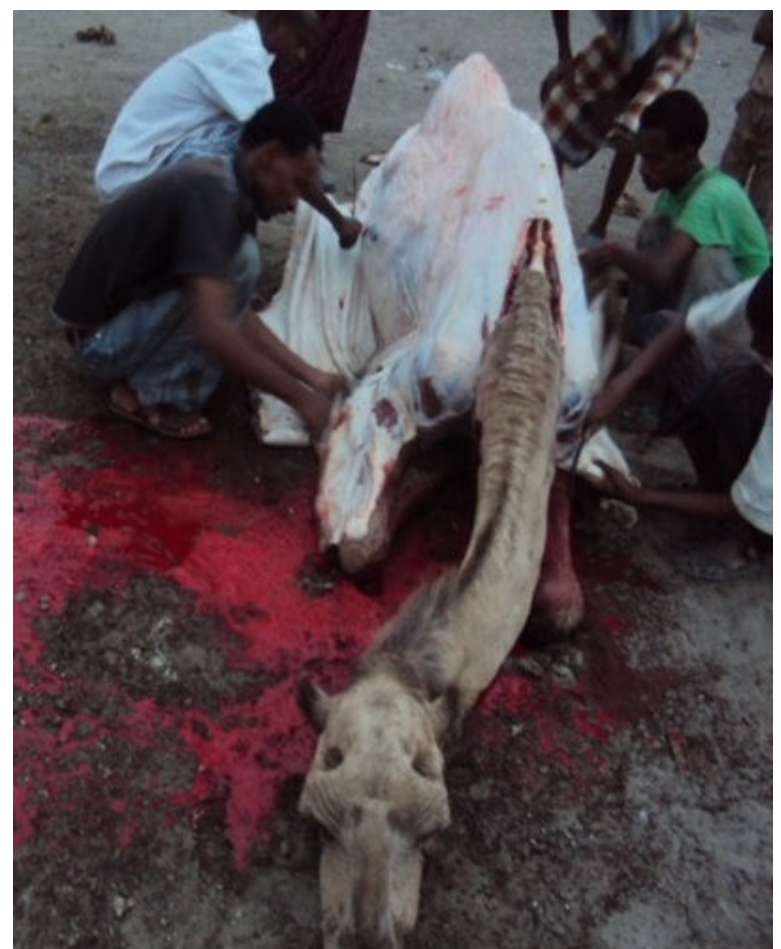

Figure 6: Flying of camle skin; note that the flying was takes place by cutting the skin along the back and then cutting into small pieces while flying.

According to Kagunyu and Matiri (2012) in Kenya camel hides are used to make the roofs for traditional pastoral houses, for making ropes, guards, drums, seats, sandals, praying mats used by Muslims, and water and milk containers. Moreover, vegetable tanned camel hides by pastoral communities are used to make hand crafts such as key holders, mats, belts, folders which are sold to tourists. According to the same author camel hides tanned in Kenyan tanneries into wet blues and large amount was exported to Middle East and to other African countries. A small percentage was used by domestic leather manufacturers, where they were used to make leather boots used by Kenyan army, shoes, saddles, bags and jackets among other products.

\section{CONCLUSIONS}

Camel is a good source of meat and has high potential as meat animal. It has also a big role in earning foreign currency through export of live camel, and processed meat. The current scenario of camel production and marketing indicated that there are lucrative market opportunities especially from Middle East and North African countries for slaughter camel. Moreover, processed camel meat can be improved in terms of quality and safety for wider distribution and marketing which would in turn improves the livelihood of pastoralists and peoples involved in this business.

There are animal ethics and welfare issues related with camel slaughtering and pre-slaughter handling. This 


\section{Mitiku Eshetu Guya and Getachew Neme}

is because slaughtering of camel was conducted in cruel manner than any other livestock species in the country. This was manifested by cutting a live camel at knee (Achilles tendon) and makes the animal to drag its hind leg with excruciating pain. Such practice will not only breach animal welfare and slaughter animals handling ethics but also affects meat quality and safety that will be harvested. Therefore, attention should be given concerning proper handling during pre-slaughter and at slaughter to reduce animal suffering and to maintain quality of harvested meat. Proper feeding and slaughtering of camel in good body condition is another area that need due attention for production of good quality and quantity camel meat.

According to compassion in World Farming, all slaughter should be humane, which means that animals must be stunned prior to slaughter using a method that causes immediate unconsciousness or, in the case of gas stunning, does not cause distress during the period before loss of consciousness. Both EU and UK legislation on the welfare of animals at slaughter allow exemptions for religious communities. Whilst valuing religious freedom, this should not extend to practices which inflict suffering on animals.

Drafting regulation and getting approved on procedures to be followed in camel slaughtering will have a paramount importance to safeguard camel against unethical and cruel handling during slaughtering. Establishment of modern slaughter house could also serve the purpose and will enable production of quality and quantity camel meat. Training of individuals involved in camel slaughtering, and camel meat traders about humane handling and slaughtering of animal will contribute in averting the current inhumane and substandard slaughter practices.

Future research efforts need to focus on exploring the potential of the camel as a source of meat through multidisciplinary research approach. Improved meat technology and marketing is equally important. Further research is also recommended for in depth study of camel meat preservation and its quality. Possibilities of hide and leather production and its quality could be the other issues that need to be addressed in the future.

\section{Conflict of Interest}

Conflict of interest none declared.

\section{REFERENCES}

Allen, C. (1998). Assessing animal cognition: Ethological and Philosopical perspectives. Journal of Animal Sciences 76: 42-47.

Barton, P.A. (1984). Influence of Halothane genotype on Meat quality in pigs subjected to various pre-slaughter treatments. $30^{\text {th }}$ Proceeding of Europeean Meat Research Workers, Bristol, England, pp 8-9.
Sci. Technol. Arts Res. J., July-Sep 2015, 4(3): 123-128

Bekele Tafesse (2001). Studies on Cephalopina titilator, the cause of "Senegal" in camels (Camelus dromedaries) in Semi-arid area of Somali State, Ethiopia. Tropical Animal Health and Production 33: 489-500.

Faye, B., Bengoumi, M., Cleradin, A., Tabarani, A. and Chilliard. Y. (2001). Body condition score in dromedary camel: A tool for management of reproduction. Journal of Agricultural Science 13: 01-06.

Foxwell, S. (1999). The camel marketing of System of Kenya: Process, constraints and improvements, University of New Castle.

Gitao, G.C. (2006). Camel Husbandry: A practical Guide to camel Husbandry, Immediate Communications Ltd, Nairobi.

Grandin, T. (1994). Euthanasia and slaughter of livestock. Journal of the American Veterinary Medical Association 204:1354-1360.

Gregory, N. G. (1998). Animal Welfare and Meat Science. CABI publishing, UK.

Humane Slaughter Method, Wikipedia the free Encyclopedia. http://en.wikipedia.org/wiki/Humane SI aughter Act

IRDMP. (2004). Integrated Resource Development Master Plan (IRDMP) Study of Dire Dawa. Addis Ababa, Ethiopia.

Kagunyu, A. and Lengarite, M. (2012). Analysis of Camel Hides Production, Marketing and Utilization by Local Leather Goods Manufactures in Kenya. In: Proceedings of the $3^{\text {rd }}$ Conference of the International Society of Camelid Research (ISOCARD), Sultan Qaboos University, Muscat.

NBIIA. (2011). Norman Borlaug Institute for International Agriculture. 2011. Ethiopia's Meat and lives animal exports registered dramatic increase, SPS-LMM. Norman Borlaug Institute for International Agriculture bulletine No. 22

Tezera Getahun (1998). Characterization of camel husbandry practices and camel milk and meat utilization in Jijiga and Shinile Zone , Somali Region, MSc Thesis, Alemaya University of Agriculture.

Voisinet, B.D., Grandin, T., O'Connor, S.F., Tatum, J.D. and Deesing, M.J. (1997). Bos indicus cross feedlot cattle with excitable temperaments have tough meat and a higher incidence of borderline dark cutters. Meat Science 46:367-377.

Warriss, P.D., Brown, S.N. and Adams, S.M. (1994). Relationships between subjective and objective assessments of stress at slaughter and meat quality in pigs. Meat Science 38:329-340. 